\title{
The Singular Sensory Image in The Poetry of Nizar Qabbani
}

\author{
Ahmed Shahab Muhammad*, Juwan Abdwlqadir Abdulla \\ Department of Arabic Language, Faculty of Arts, Soran University, Soran, Iraq \\ * ahmadshahab1578@gmail.com
}

\begin{abstract}
KEYWORDS: $\quad$ Image, Sensory, Singular, Audio, Visual.
\end{abstract}
Crossref doi https://doi.org/10.51345/.v33i1.460.g258

\begin{abstract}
:
The sensational imagery in literary works is a viable artistic way to discover the merits of the poetic text and to identify the semantics of structures and phrases. The research focused on the sensational imagery of the poet Nizar according to the human senses. It is apparent that sensational imagery depends, in the first place, on the visual, auditory, olfactory, tactile, and gustatory senses of human beings. I have tried hard to collect examples from the poetry collections of the poet to determine the meaning and function of the sensational imagery in the texts. I have limited my study to some selected example works of the poet, taking into account the sheer amount of sensational images that he has used in his books which might be difficult for this research to cover or count without affecting the credibility required in a scientific research. It was possible for the researcher here to collect example evidences of sensational imagery as being used in the poems and categorize them accordingly as well as clarifying their meanings and the connotations behind these texts. I preferred to focus on the most common sensational imagery in the poet's collections because they represent the artistic depiction of the experiences and emotions of the poet's literary world and interests. It can be said that sensational imagery is one of the basic components from which poets derive their poetic depiction and use it to decorate their poetic texts with an aesthetic painting. Through the mechanism of induction in Nizar's poetry, it becomes clear to us that there are singular sensational images in all their patterns and forms, which in turn clearly reflect the poet's experiences and emotions.
\end{abstract}




\title{
الصورة الحسية المفردة في شعر نزار قباني
}

\author{
أحمد شهاب محمد*، أ.م.د. جوان عبدالقادر عبدالله

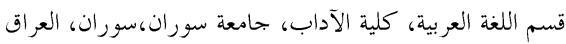 \\ * ahmadshahab1578@gmail.com
}

$$
\text { الكلمات المفتاحية الصورة، الحسية، المفردة، السمعية، البصرية. }
$$

Crossref doi https://doi.org/10.51345/.v33i1.460.g258

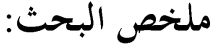

الصورة الحسية في العمل الأدبي طريقة فنية رائعة للولوج داخل حيثيات النص الشعرى والتعرف على دلالات التراكيب والعبارات، وقد سلط البحث فى هذا الجزء على الصورة الحسية عند الشاعر نزار قبالن على حسب أنواع الحواس عند الإنسان، ومعلوم أن الصورة الحسية تتكأ في المقام الأول على الحواس السمعية والبصرية والذوقية الشمية واللمسية عند بنى الإنسان، وقد حاولنا جاهدين جمع أمثلة من دواوين الشاعر موضع الدراسة، لتحديد المعنى والوظيفة للصورة الحسية على حسب ما يتطلبه النص، وقد آثرت في هذا العمل أن استعرض لبعض الأمثلة التي تناثرت بكثثرة أعمال الشاعر وأعرض لهذه الصور الحسية على سبيل المثال وليس على سبيل الحصر نظرا لضخامة الكم الذى عجت به دواوين الشاعر نزار قبالن من صور حسية، مما قد يستعصى على البحث حصر هذه الصور والتكهن ببيان عددها وقد أكون في ذلك مبتعدا عن المصداقية التى يتطلبها البحث العلمي. وقد تيسر للبحث هنا جمع أمثلة لما ورد في أشعار الشاعر من شواهد للصورة الحسية، ومن ثم تصنيفها على حسب الحاجة، وبيان توضيح المعالي والدلالات التى تكمن خلف هذا النص، والصورة الحسية، وقد آثرت أن نقف عند

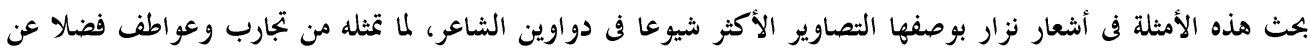

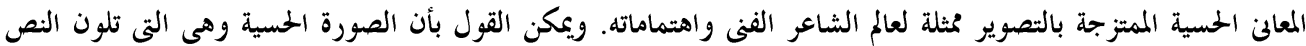

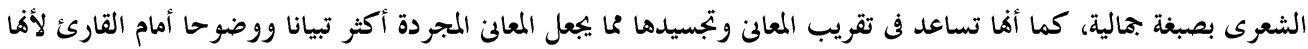

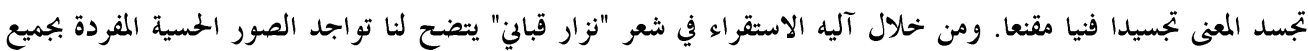
أنماطها وأشكالها، والتى هى بدورها تعكس لنا بكل وضوح تجارب الشاعر وعو اطفه، وسنستعرض في بحثنا هذا الصورة المفردة لدى الشاعر نزار قبالن، محاولين الوقوف عند بدورة أبرزها. 


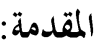

تصنف الصورة المفردة إلى أربعة أصناف هي:

أولا: الصورة السمعية:

الصورة السمعية هى الصورة التى تعتمد في تكوينها على حاسة السمع، سواء كانت أصوات لبشر أو أصوات غير بشرية، وحاسة السمع هي التي تمكن الإنسان من تحسس الأصوات والحكم على معيار

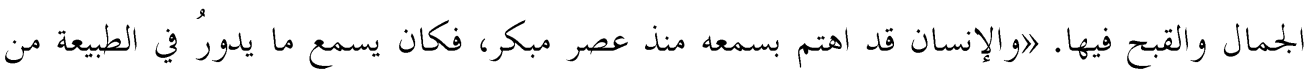

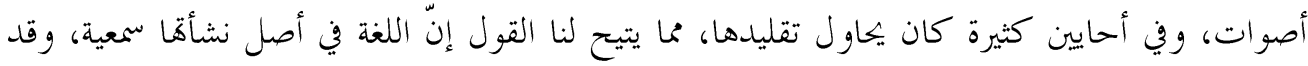

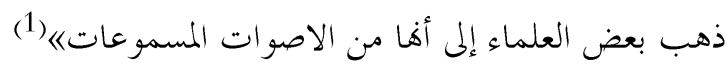
أن حاسة السمع من أهم الحواس التي يعتمد عليها الإنسان في تكوين ثقافته فقدمت حاسة السمع في

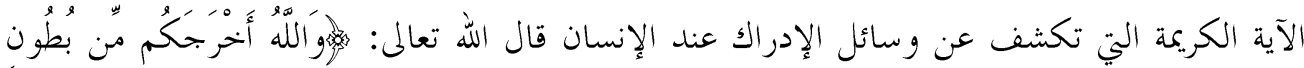

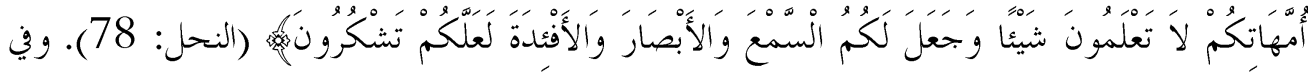
شعر نزار حضور كبير وواضح للصورة السمعية، فقد ارتكز نزار في مواضع عدة في قصائده على

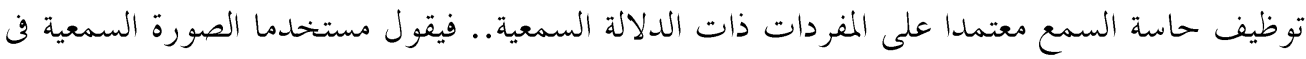
قصيدة "هوامش على دفتر النكسة "(2) التي تناول فيها أجواء النكسة والأسباب التي أدت إلى هذهة الهزبيمة المنكرة:

$$
\text { إذا خسرنا الحرب لا غرابه }
$$$$
\text { بكل ما يملك الشرقي من مو اهب الخططابه }
$$$$
\text { بالعنتريات التي ما قتلت ذبابه }
$$$$
\text { لأننا ندخلها.. }
$$$$
\text { منطق الطبلة و الربابه. }
$$

والصورة السمعية حاضرة في هذه اللوحة الشعرية من خلال مفردة (الخطابة) قصيدة نزار قباني

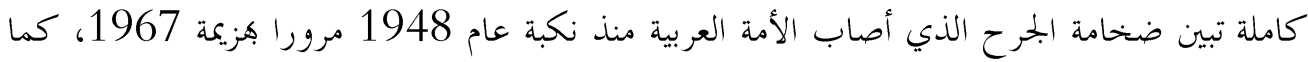
توضح أن الثقافة العربية تتعلل بأسباب واهية كما أن السياسات العربية تسير من انتكاسة إلى انتكاسة،

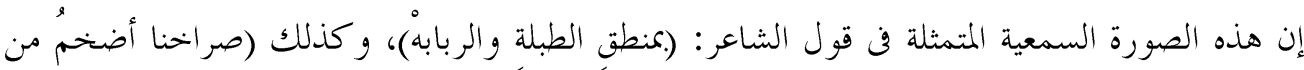

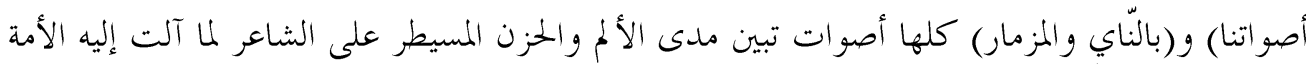


العربية من تخاذل واتكالية وكأها اعتادت على الهزيمة ، والشاعر ببراعة جمع بين الصورة السمعية والاستعارية ليعبر عن حالة الخزى والذل الذى يعيشه العرب في هذه الحقبة الزمنية التى كثرت فيها

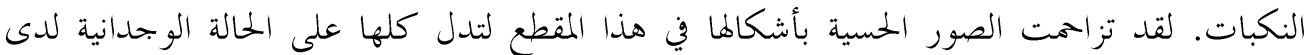
الشاعر فكان التجسيم في "صراخنا أضخمٌ من أصواتنا" قد حققت الصورة السمعية تأثيرا حين استعمل الصور الحسية التي جاءت في صورة الاستعارة التصريجية في قوله "بالنّاي والمزمار" وتألق

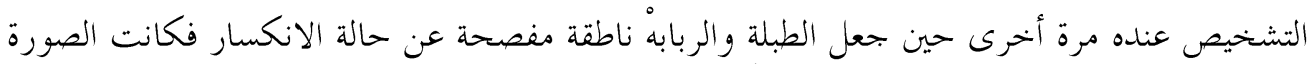

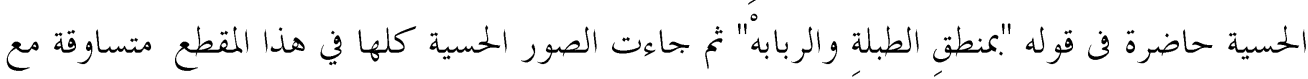
انفعال الشاعر والحالة الوجدانية الحزينة له. ومن الصور الحسية السمعية صورة للمجاهدة الجزائرية جميلة بو حيرد التى كانت بارعة فى زرع القنابل

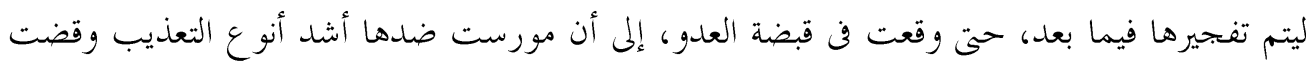

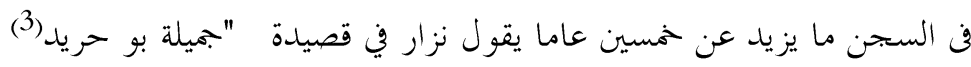

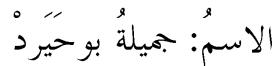

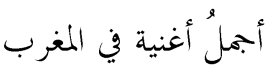

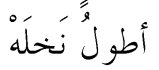

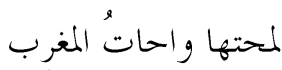

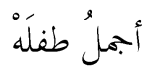

$$
\begin{aligned}
& \text { أتعبت الشمس وَ ولم تتعب }
\end{aligned}
$$

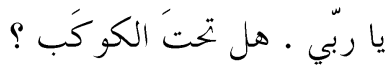

$$
\begin{aligned}
& \text { يو جدُ إنسانْ } \\
& \text { يرضى أن يأكُلَ .. أن يشرَب إنسان } \\
& \text { من لخم مُجاهدة تُصلب. }
\end{aligned}
$$

ففى قول الشاعر (أطول أغنية بالمغرب) صورة حسية سمعية تحرك مشاعر الأمة العربية كلها، فقد

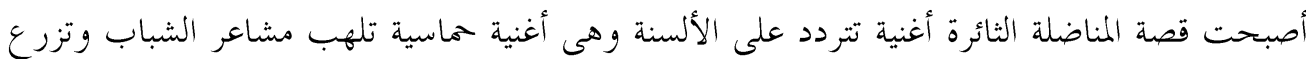
الافتخار في قلوب الشيوخ. وتؤكد الصورة الحسية السمعية التي رسمها الشاعر للمناضلة حضوراً للإبداع اللغوى عند الشاعر، إذ أنه يستعمل من الكلمات ما يتناسب مع الصورة في فئ فهو يستعمل اللغة استعمالا فنيا رائعا، فاعتمد الشاعر في قوله (أطول أغنية بالمغرب) على الاستعارة التصريحية في رسم 
صورته الحسية بجسداً للمعنى والفكرة حيث صور قصة "جميلة بوحريد" بالأغنية ملوناً إياها بنقاء الوجدان وصدق التجربة.

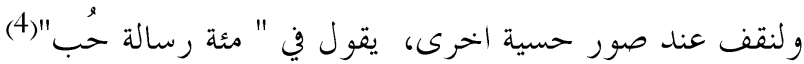

$$
\begin{aligned}
& \text { إشربي فنجان قهوتكُ. } \\
& \text { واستمعي بهدوء إلى كلماتي .. } \\
& \text { فربمّا.. - ماء. } \\
& \text { لن نشربَ القهوة 'مَاً...مرةً ثانية } \\
& \text { ولن يُّاح لي أن أتكلم مرةً ثانية }
\end{aligned}
$$

يقدم لنا الشاعر فن هذه المقطع صورة كلية رائعة تداخل فيها الحواس في التعبير عن جماليات التركيب

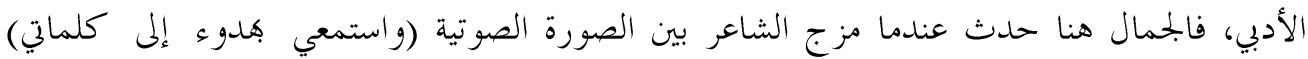

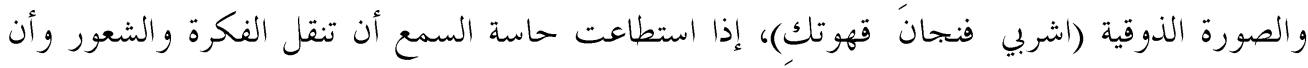
تنهض بلدور المعبر عن مكنونات السرائر ومستودعات الضمائر، فالهدوء يدرك عن طريق حاسة السمع، ويتألق الأداء الأسلوبي فن مكونات الصورة الحسية حيث اعتمد الشاعر هنا على الأسلوب الإنشائي المتمثل في الأمر في قوله (استمعى) ناقلا إيانا فن فضاء رحب من المعانى القائمة على الخيال الرائق.

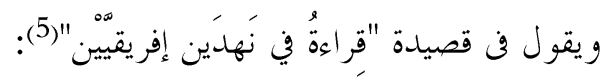

$$
\begin{aligned}
& \text { أعطيني وقتاً. . }
\end{aligned}
$$

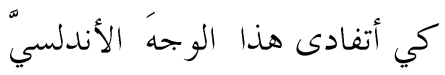

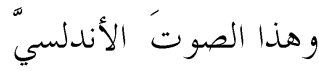

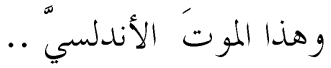

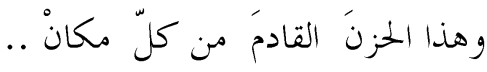

$$
\begin{aligned}
& \text { أعطيني وقتاً يا سيّدتي } \\
& \text { كي أثنبَّأ بالطو فانْ . }
\end{aligned}
$$

ففي قول الشاعر (وهذا الصوت الأندلسي) صورة حسية اتكأ الشاعر فيها على المجاز لإيصال غاية من

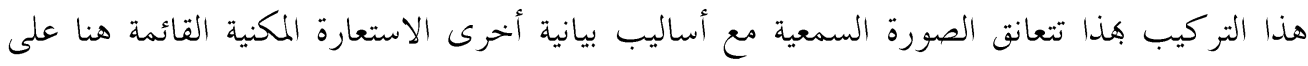
التشخيص، وقد أسهمت الصورة الحسية في الدلالة المراد التعبير عنها، كما حققت دلالة إيحائية أخرى بنح الشاعر تقديمها للمتلقي ببراعة وهذه مقدرة فنية يتصف بها الشعراء الموهوبون، إذ إن هذه 
السمة تحققت في قوله: (وهذا الصوت الأندلسي)، وأفرزت دلالات ومعانى هي من نتاج الصورة الحسية التي وسمت معالم النص بالوفاء والعرفان، إذا صورة ملونة بذكريات جميلة لتاريخ الأندلس ركس الجميل، مخضبة بمشاعر الشوق لهذه البقعة الغالية التي ظلت تحت الحكم العربي لما يقرب من ثمانية قرون.

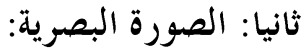
مثا لا شك فيه أن حاسة البصر من أقوى الحواس الإنسانية، وكثيراً ما يـتأمل الشاعر الموجدات ويراها

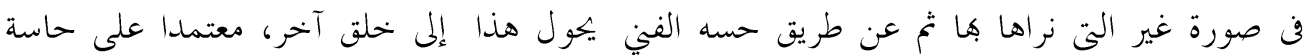
البصر. ومن هنا نستطيع أن نقول: 》الصورة في أساس تكوينها فهي بنت البصر والرؤيا《)(6). ورحاسة البصر أكبر الحواس قيمة عند الإنسان، والإنسان يحافظ عليه بكل ما أوتى من قوة لأنه آلة الإدراك لك الك

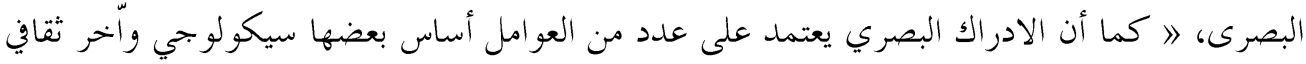

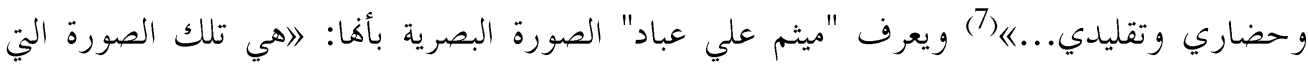

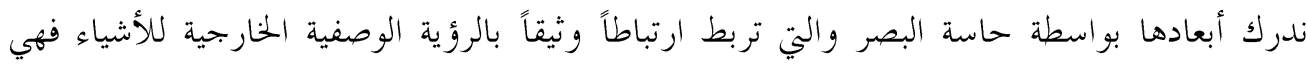

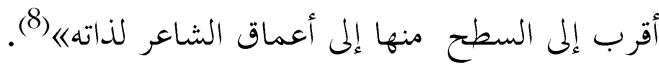
وحاسة البصر هي الوسيلة التي يدرك ها الشاعر جمال الطبيعة ومفاتنها، فيتأمل الشاعر، ثم يصور بأسلوبه أدق التفاصيل المرئية في صورة حسية تعتمد على الخيال الرائق والإحساس المرهف. وعند نزار تسجل

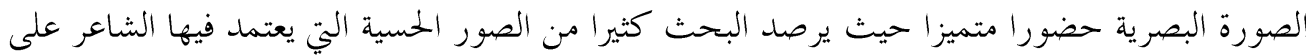
المفردات البصرية ويمكن تعيينها -أي الصورة الحسية- داخل النص الشعرى من خحلال الألفاظ الدالة

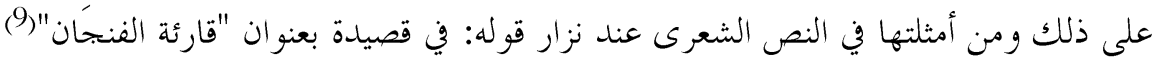

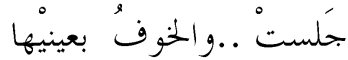

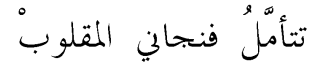

$$
\begin{aligned}
& \text { قالت: يا وكَدي .لا تحزنْ }
\end{aligned}
$$

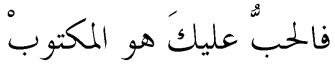

ففي قول الشاعر (جَّست ..والخوف بعينيها) صورة حسية بصرية اتكأ الشاعر فيها على الاستعارة

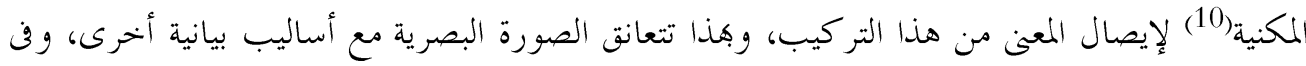

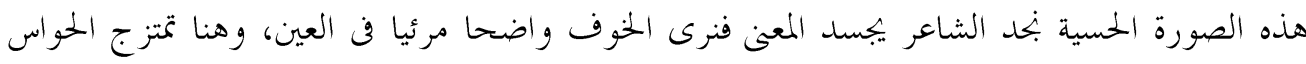
بعضها ببعض لتمنح التركيب التصويري ميزة تميزت ها قصائد الشاعر موضع الدراسة وهنا تتجلى 
الوظيفة الكبرى للصورة الحسية وهى أها تصير الترجمان الأول للوجدان والشعور. ويقول في قصيدة

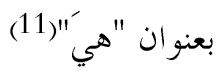

$$
\begin{aligned}
& \text { سمعتُ قبلي من خلال الدجىَ }
\end{aligned}
$$

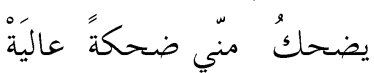

$$
\begin{aligned}
& \text { وكانَ.. أن رأيتها تختبي صنها } \\
& \text { من جنبيَ الأيسر .. في الزاوية }
\end{aligned}
$$

وف بعض الأحيان بحده يستند في تكوين صورته الحسية البصرية على ذكر دلالات الكلمة المفردة التى تئي

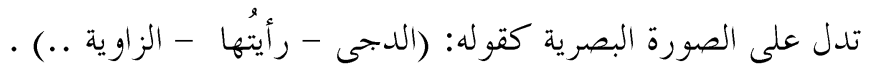

إن البحث عندما يعود إلى الجو العام للقصيدة وعنواها - بغية الولوج إلى حيثيات الصورة الحسية هنا يلاحظ ان القصيدة كلها مشبوبة بجو من الحزن والأسى، وهو ملحوظ من عنوان القصيدة ذاته

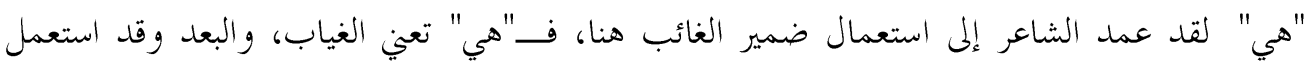

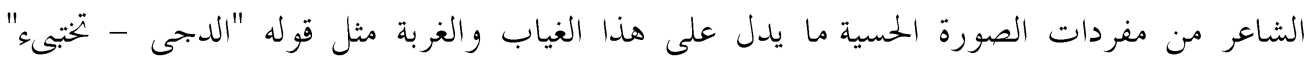
فالشاعر يوظف صوره الحسية البصرية بطريقة فنية رائعة، فهي دائمًا منسجمة مع الجمو العام للقصيدة مئه

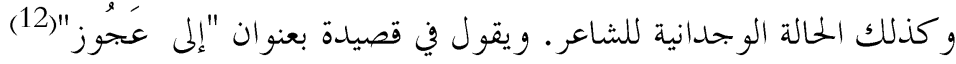

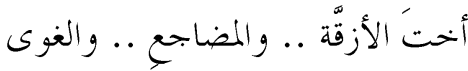

$$
\begin{aligned}
& \text { و الغرفة المشبوهة المتلألئه. }
\end{aligned}
$$

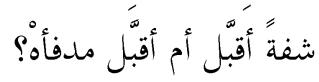

$$
\begin{aligned}
& \text { والإبطُ .. أية حفرةٍ ملعونة إنة }
\end{aligned}
$$

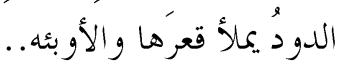

الصورة الحسية البصرية هنا لها قرائنها الدالة عليها من مفردات بصرية كقوله: (المتلألئة - شفةً - الدود

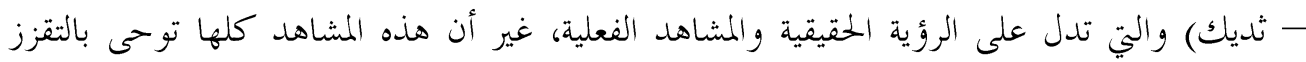

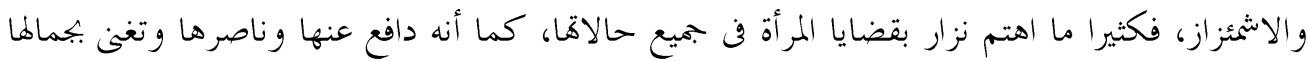
في مواضع عدة، إلا أنه احتقرها وقلل من شأها كما هو الحال في هذا المقطع، فهو يرسم صورة حسية بصرية مقززة لتلك العجوز المتصابية التى تبيع جسدها من أجل الثراء و الكسب المست المادي. يقول في : بتحلّيات صوفيه (13) عندما يمتزجُ الأخضر، بالأسود، بالأزرق، 


$$
\begin{aligned}
& \text { بالزيتيّ، بالوردي، في عينيك، يا سيّدتي } \\
& \text { تعتريني حالة نادرة. } \\
& \text { هي بين الصحو والإغماء، بين الوحي والإسراء، }
\end{aligned}
$$

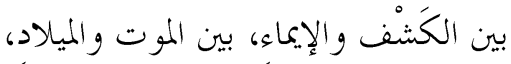

في هذه السطور رسم الشاعر صورة حسية اتكأ فيها على توظيف خاصية الألوان باعتبارها من معطيات

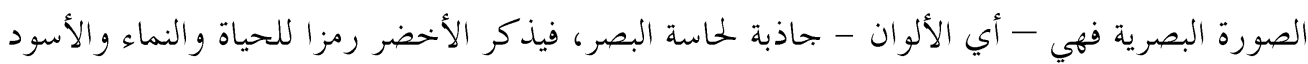

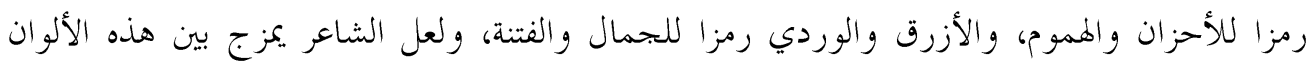

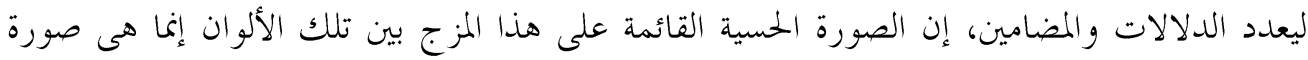
لجمال تلك المحبوبة التي جمعت كل هذه المفاتن والمحاسن في عيوها، مما جعل الشاعر متحيرا أمام هذا كله فنراه يعيش مفارقات عدة بين الصحو والإغماء، والموت و الميلاد.

ثالثا: الصورة الذوقية: - مالم

ومن الصور التي درج استعمالها في الدراسات الأدبية الصورةٌ الذوقية؛ فقد كان توظيفها كثيرا

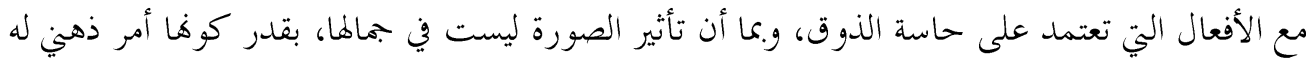
علاقة بالإحساس و الذوق؛ فإننا بند في الخطاب النقدي القليم حضورا لبعض الكلام الذى يصدق عليه القول أن به صور ذوقية، من ذلك ما روي عن حماد الراوية: اأنه سئل عن شعر عمر بن أبي ربيعة(14)

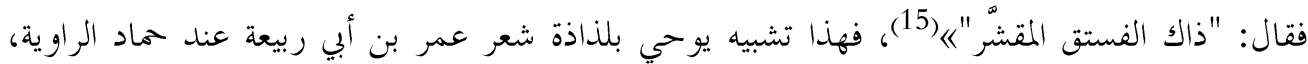

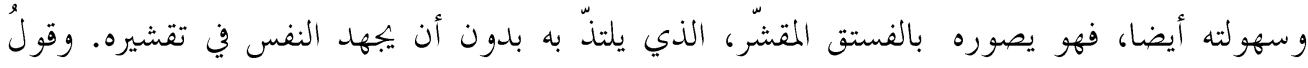

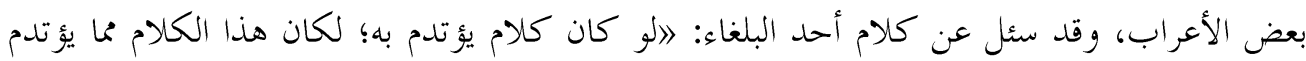

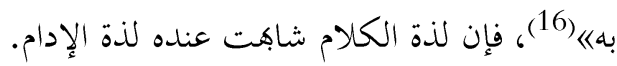
والصورة الذوقية شائعة في نقد أبى هلال العسكري، ومن ذلك قوله عندما ملدح كلام أعرابي قائلا:

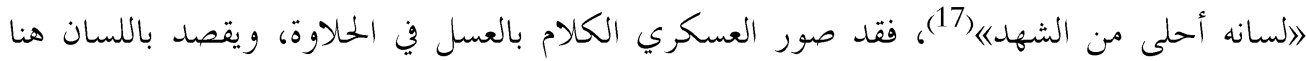
الكلام؛ لأن الكلام آلة اللسان. حاسة الذوق من الحواس التى لها أهميه كبرى في إدراك محتويات البيئة

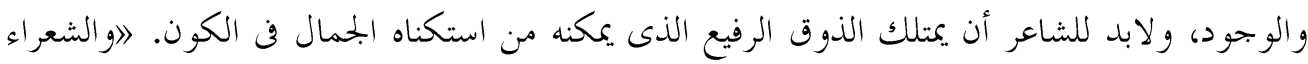

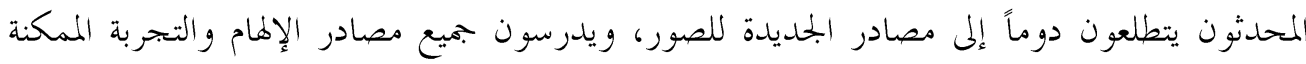
ليكتشفو إرقاً جديدة للتعبير عن انفسهمهان (18) 
وتأتي الصورة الحسية الذوقية في المرتبة الثالثة، مقارنة بالصورتين السمعية والبصرية الوتكتسب الألفاظ المستعارة من حاسة الذوق قدرة خاصة على تقريب المفاهيم و المعاني المجردة بكيث تسحبها من دائرةا، و تنقلها إلى دائرة الذوق ولوازمه، وهنا تبرز طر افة الاستعارة فإذا بالأسى، والغرام، والشعر .. تستحيل

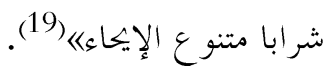
و الصورة الذوقية قائمة على حاسة التذوق و آلة الذوق هى اللسان الذى يمكن الإنسان من معرفة طبيعة

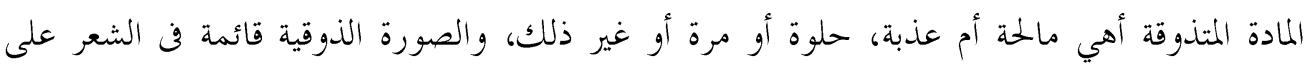
المفردات التي تشير إليها بطريقة مباشرة أو غير مباشرة وتعرف بالصورة التي تثير خيال المتلقي ليتذوق الطعم المرسوم في البيت الشعري. 》ا بمعنى هذه الصورة تستمد خصوصيتها من حاسة الذوق ينفعل بما

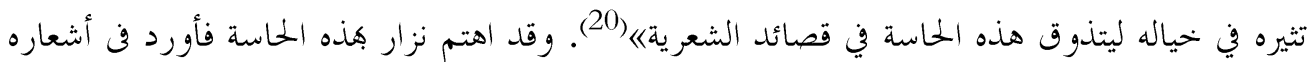

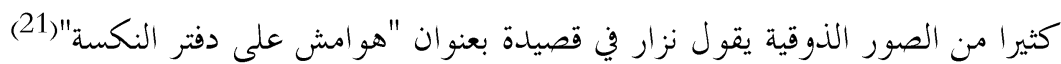
مالحة في فمنا القصائد فئد

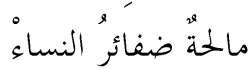

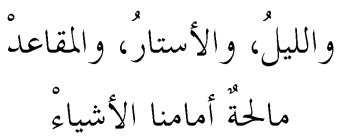

في قول الشاعر (مالحةّ في فمنا القصائد) صورة حسية ذوقية، استند فيها الشاعر على الصورة

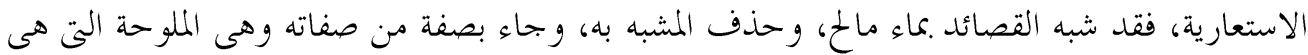
أساس التكوين البنائى للصورة الذوقية، وسر جمالها هنا التجسيم، الذى هو من معطيات الصورة في النص، وقد استعان الشاعر هنا بالصورة الحسية ليصف لنا لحظة الحزن والأسى المسيطر عليه، عقب الهزيمة التي عانى من ويلاتها العرب، مسلطا الضوء على شتى جوانب الحياة العربية البائسة، و كأنه يقدم

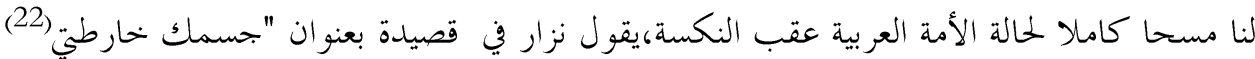
يا رمل 'البحر، ويا غابات الزيتون

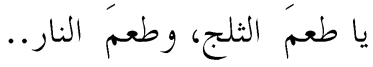

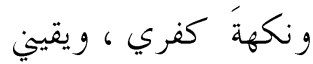

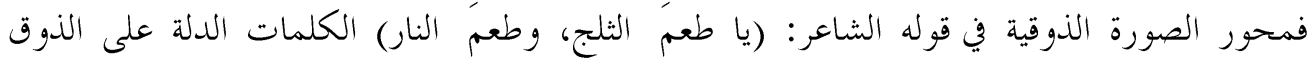
كقوله: (طعم) الذى استعملها الشاعر ضمن السياق اللغوي للصورة الحسية، وقد اتكأ الشاعر هنا على التركيب الاستعاري، فالمحبوبة هي سر سعادته الكبرى وهدو هوه (طعم الثلج) وسر عذابه وشقائه (طعم 
النار)، والصورة الذوقية هنا تعبر عن مدى الحيرة والمعاناة والهناء أيضا، وكلها دلالات استطاعت أن تفرزها الصورة الحسية واستطاع الشاعر أن يعبر عنها في ثوب أدبى أنيق وطريف، وهى -أي الصورة الذوقية- في ذات الوقت استطاعت أن تعبر عن المعنى في صورة بحسدة محسوسة.

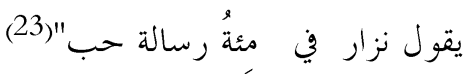

$$
\begin{aligned}
& \text { يشربُ الرجالُ الخمرة } \\
& \text { ليهربوا من حبيباهم . }
\end{aligned}
$$

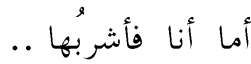

$$
\begin{aligned}
& \text { لأهربَ إليك. }
\end{aligned}
$$

في قول الشاعر: (يشربُ الرجالٌ الخمرة) صورة حسية ذوقية، وقد أسهمت الصورة الحسية في التعبير

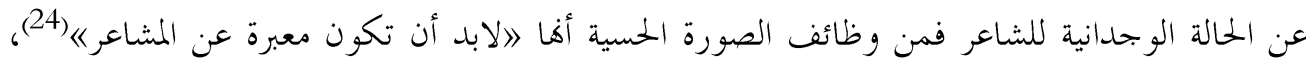
و الشاعر شديد التعلق .كحبو بته لا يستطيع نسياها، حتى وإن شرب الخمر وغاب العقل والإدر اك فهو لا لا

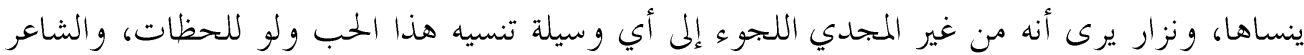

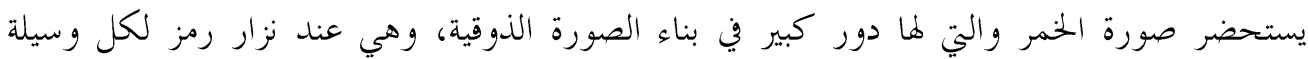
تستطيع أن تنسيه هذا الخب، فكثيرا ما يهرع العشاق إلى الخمرة للنسيان إلا أن شاعرنا يلجأ إليها فلا

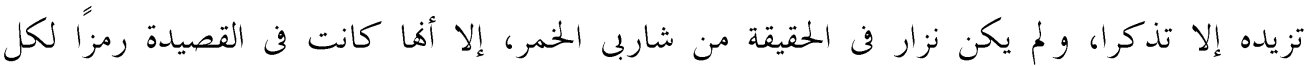
الوسائل التى قد يستعين هـا الإنسان للنسيان، فهي صورة حسية ذوقية قائمة على التركيب الاستعاري،

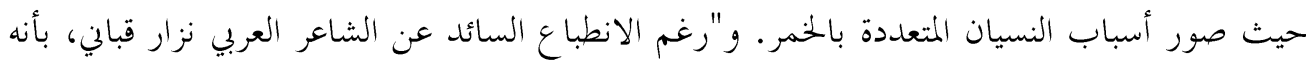

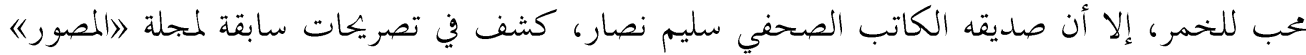

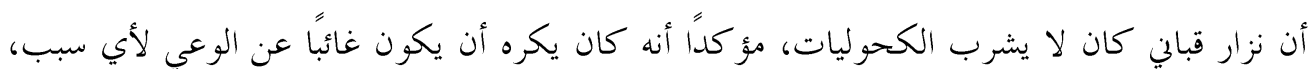

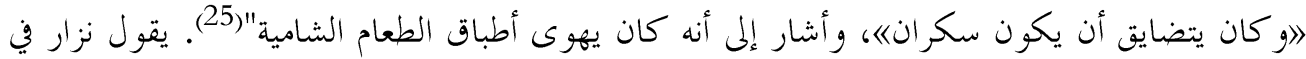

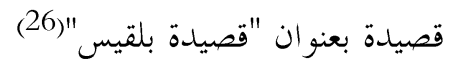

$$
\begin{aligned}
& \text { شُكر أ لكم . . } \\
& \text { شكراً لكم . . }
\end{aligned}
$$

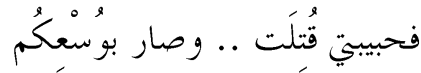

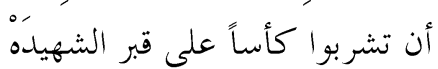

وقصيدلتي اغْتِيلت .. 


$$
\begin{aligned}
& \text { وهل من أُعَّة في الأرضِ .. }
\end{aligned}
$$

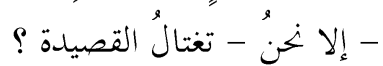

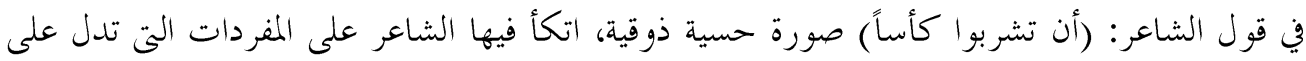
الذوق متمثلا ذلك في الفعل (تشربوا)، وقد قدم نزار صورته الذوقية من خلال التمثيل الخطابي، حيث صنت

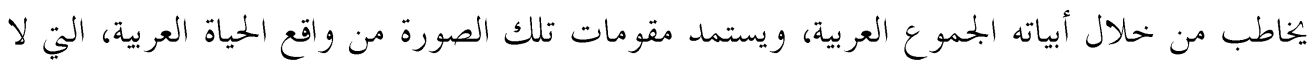

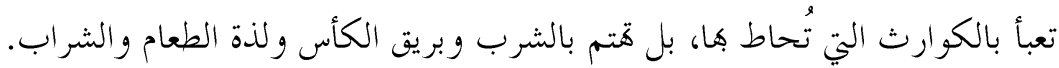
و نلاحظ أن كلمة (تشربوا) وظفها الشاعر في إطار السياق اللغوي الذى يولد في النفس نشوة عارمة

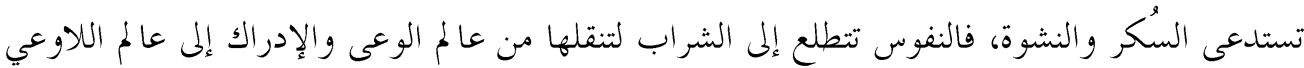

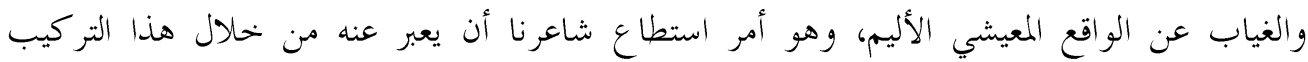

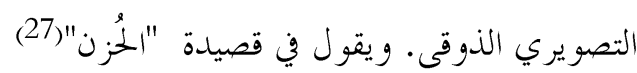

$$
\begin{aligned}
& \text { وحَكَمتُ بأنْ تتزوَّجين } \\
& \text { بنْت وُ السُلْطَانْ. . } \\
& \text { تَلْكَ العَينَاهَا . . } \\
& \text { أصفى مِنْ ماء الحُلْجَانْ } \\
& \text { تنلكَ الشَفتَاها.. } \\
& \text { أشهى من زَهْر الرُمَّانْ }
\end{aligned}
$$

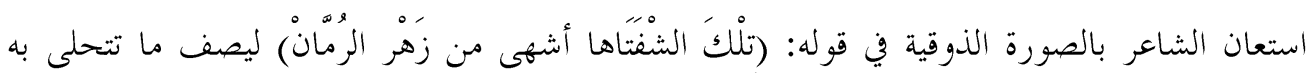

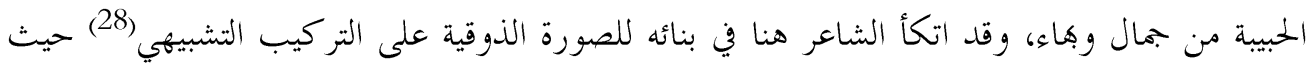

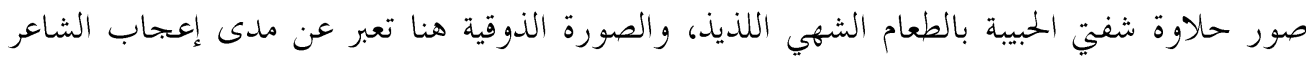
هذه الخحلال الفاتنة، ولا شك أن الصورة الحسية تنساق في إطار الجو العام للأبيات فالحديث عن الغزل الصريح لا يناسبه إلا المعاني الحسية التي تصور هذا الجمال وتظهره للحواس كي تعبر عن مكنونات هذا

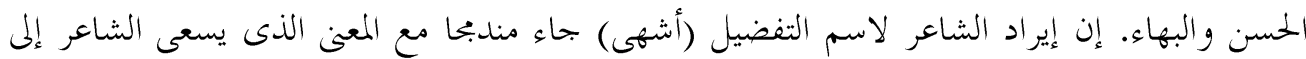

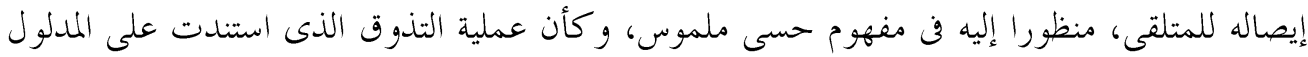
اللفظى لكلمة (أشهى) دلت على كميات من الحب والإعجاب، لغرض إظهار هذا الجمال الرائع، وأعتقد أن نزار يسعى في عملية بتحيم المعنى وبتسيده من خلال هذه الصورة الذوقية. 
الصورة اللمسية هى الصورة التي تعتمد \على حاسة اللمس للى الانسان، والتأتير فيها وسميت بالصورة اللمسية لأها تعتمد على حاسة اللمس وإحساساتا. إذن الصورة اللمسية تستند إلى حاسة اللمس متمثلة ي اليد لان اليد هي من تلمس وتشعر بالوجع أو الحر أو ماشية ذالك فهي تعتمد على إحساسات التي تشعر بها اليده|(29). ولحاسة اللمس دور فعال وكبير في استكشاف الأشياء ومعرفة الجمال الحسى من نعومة رخاوة وغير ذلك. لاوهي تعتمد على ما نتعامل معه حاسة اللمس فتأخذ أبعاد هذه الحاسة، مثل الخشونة، و النعومة، و البرودة وغيرها《(30). و وحاسة اللمس من الحواس الرئيسة في الإحساس بالجمال في

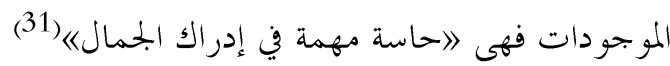
وتلعب حاسة اللمس، كغيرها من الخواس، دورا كبيرا ومؤثرا في إدراك الإحساس بالجمال، فهي آلة المبدع في استكشاف العالم من حوله، ليتسنى له بمؤازرة الخيال من إدراك الواقع إدراكا فنيا، مانحا في المتلقي إحساسا بالمتعة والراحة. و تأتى الصور اللمسية في شعر نزار كأداة للصورة الفنية، فتحدث خلالها عن إحساسه بالعالم من حوله، معتمدا على حاسة اللمس في إدراك هذا العالم وأخص بالذكر عالم المرأة، حيث نلمح في كثير من صوره ذكر الألفاظ الدالة على الصورة الحسية للمسية، مثل: (يدُك، شفيت أناملي، وبجلهُني، يدى..). ومن النماذج الدالة على هذا النوع من الصور نستعرض الأمثلة الآتية: يقول في قصيدة "يَد" (32)

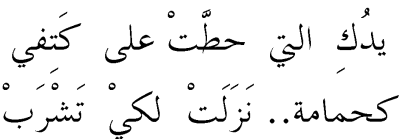

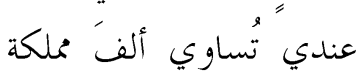
"。 يا ليتَها تبقي ولا لأنهب

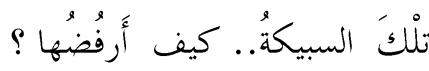

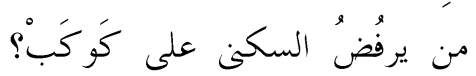
في قول الشاعر: (يلكُ التي حطت على كتفي كحمامة) صورة حسية لمسية يصف نزار ما تتحلى به الحبيبة من أنوثة ناعمة، وقد اتكأ الشاعر هنا في بنائه للصورة اللمسية على التركيب التشبيهي، عندما صور "يد الحبيبة الناعمة الحانية" بــ"الحمام الناعم الرقيق"، و الصورة الذوقية هنا تعبر عن مدى إعجاب الشاعر بما تتصف به الحبيبة من رقة ونعومة. و القرائن الدالة على الملامسة في التصوير هنا كلمة (يدك) التى هي محور بناء الصورة، وهى الأداة الأكثر التى يستكشف هها الشاعر الأشياء الملموسة، فاليد 
عندما تلامس الشاعر يرى كل شيء جميلا، والصورة اللمسية هنا تعبر عن الحالة الوجدانية للشاعر

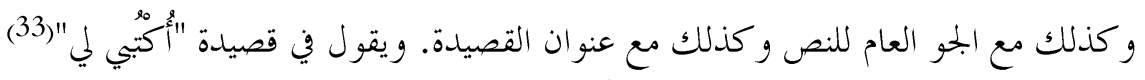

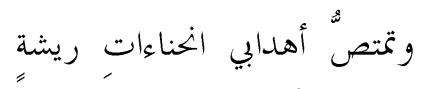

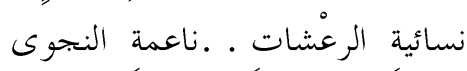

على" اقصصي أنباء نفسكِ ... بوابعثي

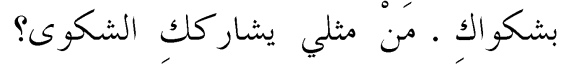

في قول الشاعر: (نسائية الرعشات . .ناعمة النجوى) صورة حسية لمسية ليصف ما تتحلى به الحبيبة من

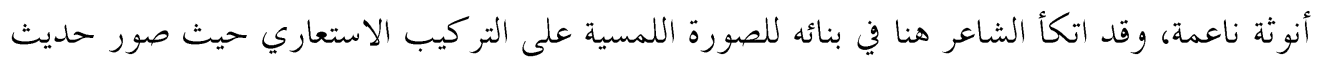
الحبيبة الشجي بشيء مادى ناعم الملمس وسر جمالها التجسيم الذى هو محور بناء الصورة الحسية.

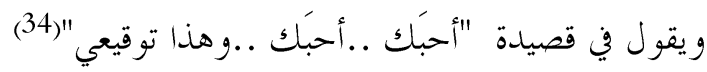

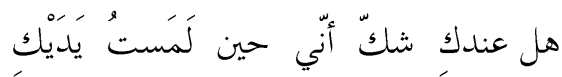

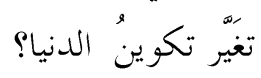

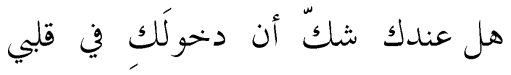$$
\text { هو أعظمٌ يومٍ في التاريخ. }
$$

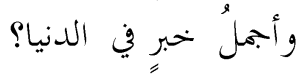

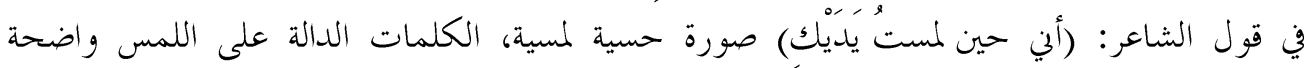

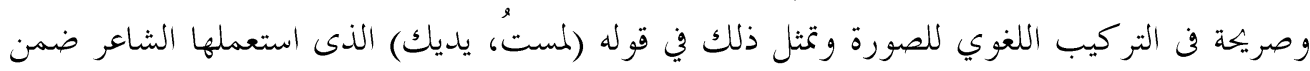
السياق اللغوي للصورة الحسية، وقد اتكأ الشاعر هنا على التركيب الكنائي، فالمحبوبة هي سر سعادته في الحياة بلمسة منها يتغير الوجود و الكون ليصير أجمل ما يكون، والصورة اللمسية هنا تعبر عن سعادة الشاعر الكبرى التي سببها القرب والتداني وهذا ما عبرت عنه الصورة اللمسية. ويقول في قصيدة "بلقيس"(35)

بلقيس..

تذبحُني التفاصيلُ الصغيرةٌ في علاقتنَا...

وتجلدني الدقائقُ و الثواني..

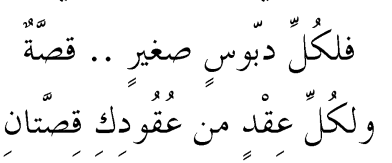




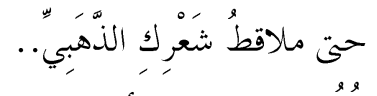

تغمروني ، كعادتها ، بأمطار الحنان

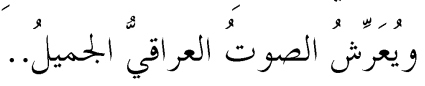

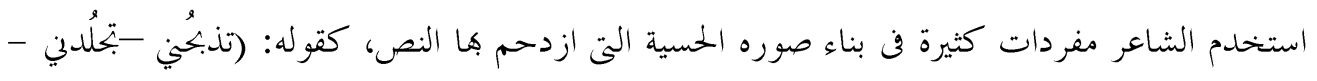
دبوسٍ صغيرٍ - تغمرلي)، وهو يتكأ فن بنائه للصورة الحسية هنا على معطيات لمسية يصور هـا مشاعره وعو اطفه. و تفصيل هذه الصور يكون كالتالي:

"تذبحيني التفاصيل الصغيرة"ا": صورة لمسية قائمة على التصوير الاستعاري فن يشبه التفاصيل

بسكين تذبح وسر جمالها التجسيم.

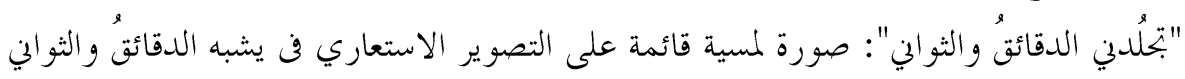

بألة للجلد و التعذيب وسر جمالما التجسيم.

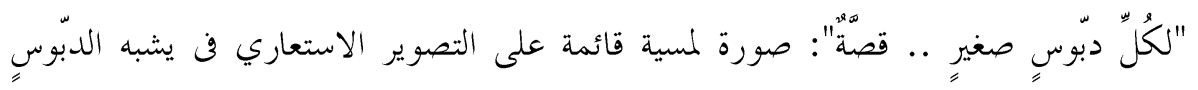

الصغير بقصة و سر جمالها التوضيح.

الخاتمة:

و نخلص إلى القول أن هذه الصور الحسية تبين لنا أن نزار يعد شاعرا عربيا يعتز بعروبته، ولذلك نرى صوره الحسية دائما تعبر عن حالة التمرد والرفض والغضب على الواقع العربي المهين وهزائم العرب. والصور الحسية بأنواعها عند نزار تعد آلية فنية رائعة في التعبير عن الحالة الوجدانية وبجسيم المعاني، و كانت كذلك أكثر التصاقا بالو اقع ومرآة صادقة للتعبير عن عالم الشاعر .عا فيه من متناقضات افراخ و اتراح إعجاب واستهجان، فكثيرا ما اهتم نزار بقضايا المرأة في جميع حالاتها، و كما أنه دافع عنها و ناصرها وتغنى بجمالها في مواضع عدة، إلا أنه احتقرها وقلل من شأها و كان ذلك جليا من خلال صوره الحسية. وقد اتكأ الشاعر نزار فن بنائه للصور الحسية على ألوان بلاغية شتى كالتشبيه والاستعارة والكناية، كما جاءت هذه الصور ملونة بعاطفة الثاعر ومعبره عن بجاربه ومتطلبات عصره. كان للصور الحسية المفردة بجميع أنماطها وأشكالها حضورا كبيرا في شعر نزار قباني، والتى هى بدورها تعكس لنا بكل وضوح بجارب الشاعر وعو اطفه الصادقة. ووعى الشاعر نزار دور الكلمات و القرائن الدالة على الصور الحسية، ولذلك جاءت هذه القرائن والدلائل من أسماء وأفعال متناثرة في النص وقد استخدمها الشاعر بطريقة فنية مشكال من خلالها صورا حسية اتسمت بالتجديد والابتكار. و وظف الشاعر صوره الحسية في التعبير عن بتحاربه وعواطفه، وصوره جاءت تتسم بالجرأة والشجاعة والإقدام على مفردات 
وتراكيب لم يطرقها الشعراء من قبله. طريقة استعمال الشاعر للصور الحسية تثبت براعته في استعمال التراكيب اللغوية استعمالا مميزا وتكشف عن مدى مقدرة الشاعر من توظيفه للثروة اللغوية والطاقات التعبيرية التي يمتلكها.

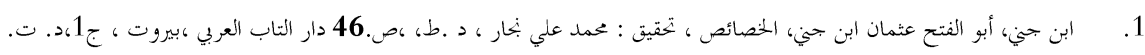

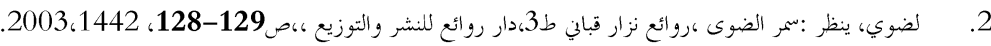

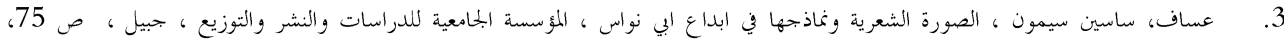
1982

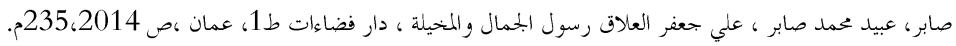

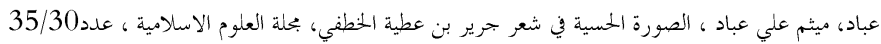
.4 .5

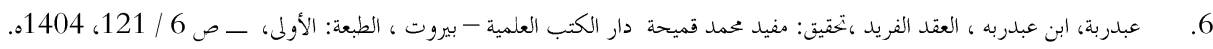
7.

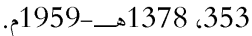

8. العسكري، الصناعتين، تحقيق محمد علي البجاوي، ومعمد ابو الفضل ابراهيم، مطبعة عيسى البابي الحببي، ط13، القاهرة، ص 279،1371هـ 1952

الجيوسي، سلمى الخضراء، الابتاهات والحر كات في شعر العربي الحديث، ترجمة: عبدالواحد لؤلؤة، مركز الدراسات الوحدة العربية، بيروت، ط1،

صايغ، وجدان عبد الإله، الصور الاستعارية في الشعر العربي الحديث: رؤية بلاغية لشعرية الأخطل الصغير، المؤسسة العربية للنشر، ط1، ص 141،

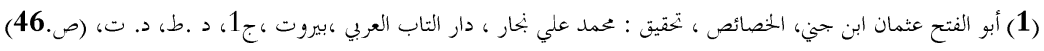

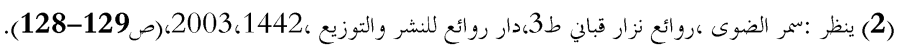

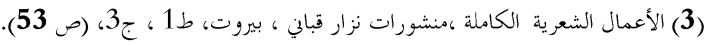

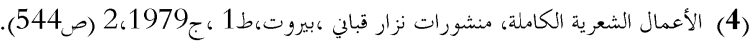

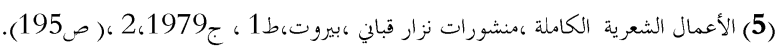

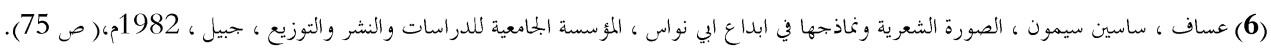

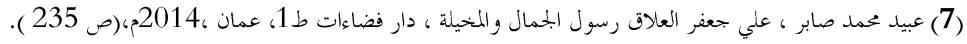

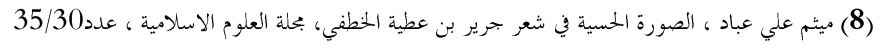




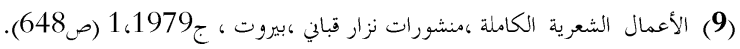

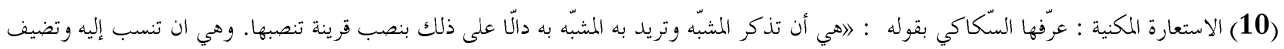

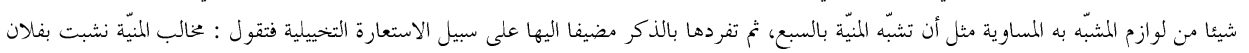

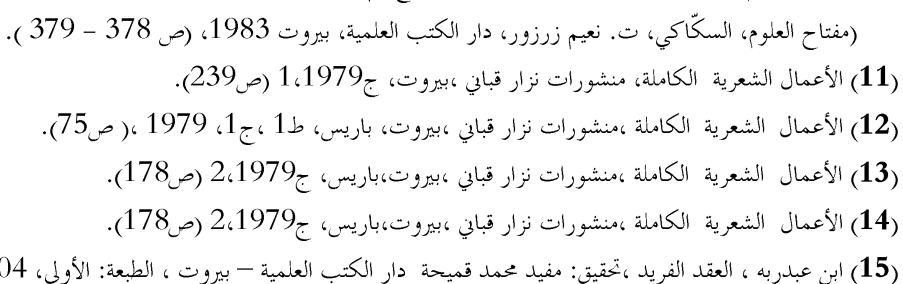

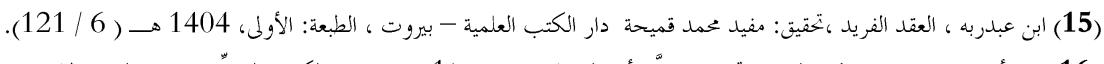

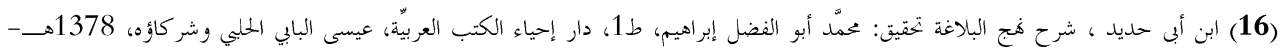
.353/18) 1959

(17) العسكري ، الصناعتين، تحقيق محمد علي البجاوي، ومحمد ابو الفضل ابراهيم، مطبعة عيسى البابي الحبي، ط1، القاهرة، 1371هـ -1952م. (ص (ص) . 279 (18) سلمى الخضراء الجيوسي، الاتحاهات والحركات في شعر العربي الحديث ، ترجمة : عبدالواحد لؤلؤة ، مركز الدراسات الوحدة العربية، بيروت ،

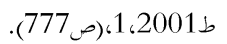
(19) صايغ، وجدان عبد الإله ، الصور الاستعارية في الشعر العربي الحديث: رؤية بلاغية لشعرية الأخطل الصغير، المؤسسة العربية للنشر ، ط 1 ، 2003، (ص) ص 141).

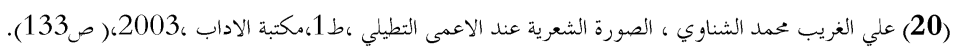

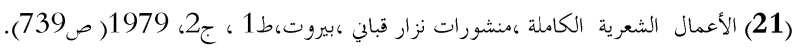

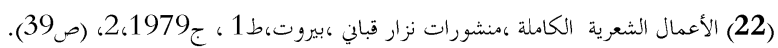

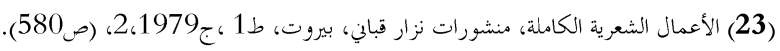

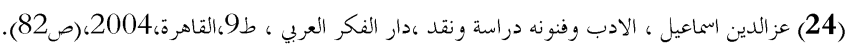

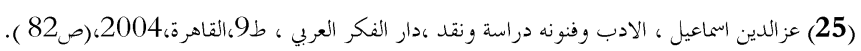

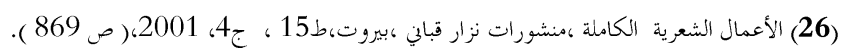

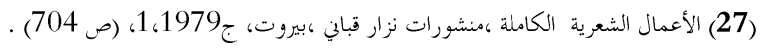

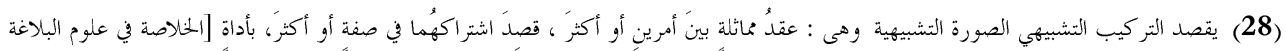

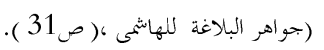

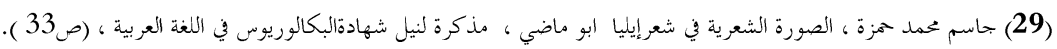

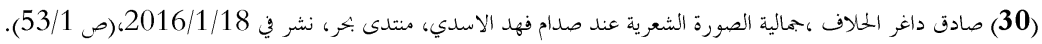

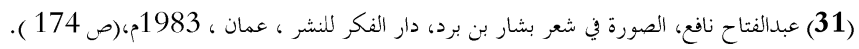

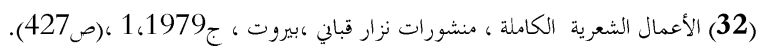

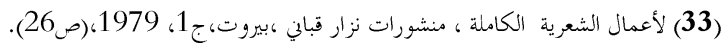

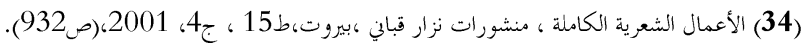

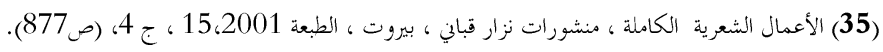

